\title{
NANOPHARMACEUTICALS: INNOVATIVE THERANOSTICS FOR THE NEUROLOGICAL DISORDERS
}

\author{
Parichehr Hassanzadeh \\ Nanotechnology Research Center, Faculty of Pharmacy, Tehran University of Medical Sciences, \\ Tehran, Iran
}

Over the past few decades, nanotechnology has emerged as a topic of great interest with a wide range of scientific investigations. This highly sophisticated technology covers a vast array of materials and devices including the high-resolution imaging for the early diagnosis of diseases and targeted delivery of genes or drugs leading to a more efficient therapeutic outcome. The limited efficacy of currently available therapeutic options against the neurological disorders have evoked tremendous efforts towards the development of novel treatment strategies. In this respect, multifunctional nanoparticles for targeted delivery of drugs across the blood-brain barrier have been designed to improve the bioavailability and reduce the side effects. Nanoengineered materials or nanodevices with ability to interact with biological systems including the nervous system have been designed for tracking the real-time dynamics of receptors in the central nervous system as well as neuronal recording or stimulation that may result in the neuroprotection or neural regeneration. Indeed, application of the cutting-edge nanotechnologies may revolutionize our knowledge about the neurophysiology and neurobiology including the cellular or molecular events in neurons leading to the more efficient treatments in central nervous system disorders. In the present article, an overview of the theranostic (therapeutic and diagnostic) potential of nanopharmaceuticals in the neurological disorders has been provided. Biomed Rev 2014; 25:25-34

Keywords: nanotechnology, nanomaterials, nanoimaging, neuronal regeneration, neuroprotection

\section{INTRODUCTION}

Injuries to the central nervous system (CNS) are clinically difficult to manage. For instance, traumatic brain injury (TBI) and spinal cord injury (SCI) usually result in the axonal degeneration and necrosis. In this respect, the victims of SCI are left paralyzed and TBI results in the disruption of brain parenchyma and permanent neuronal loss (1). The conventional treatment strategies against the neurological disorders usually mitigate the degeneration process but do not reverse the condition. In the case of neurosurgery, the risk of infections and remarkable costs may limit the effectiveness of this therapeutic approach. Furthermore, lifelong immunosuppression

Received 10 December 2014, revised 21 December 2014, accepted 22 December 2014

Correspondence to Dr Parichehr Hassanzadeh, Nanotechnology Research Center, Faculty of Pharmacy, Tehran University of Medical Sciences, Tehran, Iran. Tel.: +98 21 6695909, Fax: +98 21 66581558, E-mail: Pari_has@yahoo.com 
may be associated with various complications using artificial transplants or transplanted organs. In the past few decades, nanotechnology has emerged as a rapidly growing interdisciplinary field with a vast area for scientific investigations. From a historical point of view, nanotechnology was first proposed in 1867 by a Scottish physicist, James Clarke Maxwell, who developed statistical physics and electromagnetic theory. In 1959, the Nobel Prize Laureate physicist, Richard Feynman, made nanotech-based predictions. His concepts were further defined by Professor Norio Taniguchi from Tokyo University of Science in 1974, as 'the separation, consolidation, and deformation of materials by one atom or one molecule'. In the 1980 's, Dr K. Eric Drexler popularized the previous ideas by suggesting the manufacturing of computers or robots even smaller than a single cell $(2,3)$. In recent years, application of nanotechnology in neuroscience and neurology has provided promising research tools and theranostic (therapeutic and diagnostic) approaches leading to a better understanding of the molecular mechanisms of neurological disorders that may revolutionize the ways for therapy strategies and/or diagnostic screening (4). Application of the functional scaffold systems following the acute or chronic CNS injuries may promote the neuronal regeneration. In this respect, three-dimensional biodegradable scaffolds have been designed to induce neuronal differentiation (5). Since the blood-brain barrier (BBB) prevents the entrance of hydrophilic drugs or large molecules into the brain (6), therefore, development of the non-invasive techniques based on the modifications of the physicochemical properties of the present drug delivery systems or the conjugation of molecules with antibodies may improve drug delivery into the brain. In this respect, various advanced nanomaterials have been developed to increase the BBB crossing of drugs (7). Therapeutic potential of the highly advanced nanomaterials such as gold nanoparticles in brain tumors or myelin sheath-coated nanoparticles in multiple sclerosis has been well documented $(8,9)$.

In recent years, development of nanopharmaceuticals with improved bioavailability and half-life as well as targeted drug delivery systems using dendrimers, lipid- or polymer-based nanoparticles has attracted a considerable interest (10-12). In regenerative medicine, stem cells with ability to differentiate into various cell types including the neurons, have been entrapped into the carbon nanofibers or nanotubes for application against the neurological disorders (13). Using mesoporous nanoparticles, synthetic growth factors may be delivered into the motor neurons leading to the long term survival and func- tional differentiation (14). Moreover, biodegradable polymer nanoparticles have been designed as drug delivery nanocarriers to encapsulate either hydrophobic or hydrophilic small drug molecules and macromolecules such as proteins and nucleic acids. Biodegradable polymer systems may provide an optimum range of drug level at a longer period of time leading to the enhancement of drug efficacy and patient compliance (15). Meanwhile, development of computational models appears necessary in order to study the interactions of nanoparticles with biological environments leading to the development of more sophisticated drug delivery systems (16).

\section{THERANOSTIC APPLICATION OF NANOTECHNOLOGY IN ALZHEIMER'S DISEASE}

Alzheimer's disease is the most common cause of severe memory impairment in the elderly and has been considered as a major public health problem during the past decades. The plaques of amyloid- $\beta(\mathrm{A} \beta)$ and neurofibrillary tangles of hyperphosphorylated tau are the pathological hallmarks of Alzheimer's disease which are accompanied by the increased levels of metal ions and oxidative stress leading to the death of various neuronal subsets including the cholinergic neurons in the basal forebrain (17-19). According to the pathophysiological features of the disease, the majority of research efforts have been focused on in vivo experiments which are associated with multiple limitations (20). Based on the remarkable advances being made in nanotechnology including the development of novel devices and biomaterials for the diagnosis of CNS disorders and innovative methods for tissue regeneration, the early diagnosis and more effective treatment of Alzheimer's disease has been possible. Using the highly-advanced approaches including the fluorescence resonance energy transfer (FRET) technology and atomic force microscopy (AFM) has provided a better understanding of the molecular mechanisms of Alzheimer's disease. AFM scanning probes which are used for single-molecule imaging and characterization of biomolecules, provide a real time visualization of the process of $A \beta$ fibrilogenesis and in vivo characteristics of amyloid species (21). FRET may be used for both in vivo and in vitro systems. Using this technology, the molecular mediators implicated in the pathogenesis of the disease and subcellular localization of A $\beta$ may be identified (22). Bio-barcode assay, a highly sensitive method, is used for the identification of the disease stage based on the concentration of biomarkers $(23,24)$. Moreover, the localized surface plasmon resonance nanosensors with high sensitivity and specificity may be used for patient screening 
and evaluation of the oligomerization of $A \beta$ (25). Since the oxidative damage is an early outcome of the disease pathology, development of efficient antioxidants has been the focus of intense research. In this respect, derivatives of fullerenes have been designed which are potent free-radical scavengers and exert neuroprotective effects against glutamate-induced excitotoxicity leading to the inhibition of $A \beta$ fibrilogenesis (26). Intraventricular administration of hydrated fullerene into the rat prevented $A \beta$-induced cognitive impairments suggesting the therapeutic significance of fullerenes in Alzheimer's disease (27). Indeed, the inhibition of $A \beta$ plaque formation has been one of the most extensively investigated nanotechbased approaches. In the SHSY-5Y human neuroblastoma cell line, nanomicelles composed of phospholipids which are stabilized by the addition of polyethylene glycol (PEG) has been shown to inhibit the aggregation of $A \beta$ leading to the reduced $A \beta$-induced neurotoxicity (28). Chelating agents such as the copper-zinc chelators may also inhibit $A \beta$ plaque formation and improve the cognition. Microemulsion nanoparticles conjugated to the copper chelator, D-penicillamine, are able to dissolve $A \beta$ aggregates (29-31). In the primary cortical neuron cultures, cholesterol-bearing nanogels have been shown to reduce the neurotoxicity because of the inhibition of $A \beta$ aggregation $(32,33)$. Regarding the therapeutic potential of nano-phytochemicals in Alzheimer's disease, the nanoliposomes of curcumin have been shown to inhibit $A \beta$ aggregation and subsequent cytotoxicity, whereas, administration of free curcumin failed to exhibit a significant effect because of the low bioavailability $(34,35)$.

Based on the cholinergic deficit in the disease, current treatment options including those based on nanotechnology aim to increase the cholinergic neurotransmission. Since acetylcholine does not readily cross the BBB and has a short half-life, therefore, nanocarriers of acetylcholine such as the single-walled carbon nanotubes which are able to cross the BBB have been designed. These nanotubes were loaded with acetylcholine and restored the cognitive function in kainic acid-induced mouse model of Alzheimer's disease, while, acetylcholine showed no effect by itself (36). Moreover, poly(n-butylcyanoacrylate) (PBCA) nanoparticles encapsulated with cholinesterase inhibitors may be used for the treatment of dementia associated to Alzheimer's disease. These nanoparticles adsorb blood apolipoproteins that enable them to bind to LDL receptors on BBB endothelial cells leading to the facilitation of nanoparticle transcytosis and delivering the cholinesterase inhibitors into the brain (37). In order to increase
BBB penetration, $\mathrm{PBCA}$ nanoparticles are usually coated with polysorbate- 80 leading to the enhanced delivery of drugs into the brain (38). These nanoparticles encapsulated with the acetylcholinesterase inhibitor, rivastigmine, have significantly improved memory and spatial learning (39) indicating their therapeutic significance in Alzheimer's disease.

\section{NANOTECHNOLOGY FOR THE DIAGNOSIS AND TREATMENT OF PARKINSON'S DISEASE}

Parkinson's disease, one of the most common neurodegenerative disorders worldwide, is associated with loss of dopaminergic neurons in substantia nigra pars compacta and accumulation of $\alpha$-synuclein aggregates (Lewy bodies) in the brainstem. Currently available drugs elevate the levels of dopamine in the brain and improve the symptoms, however, they do not alter the progression of the disease process (40). The majority of drugs are administered orally, therefore, dietary proteins, gastric $\mathrm{pH}$ or rate of emptying may affect the bioavailability of drugs. Other drug delivery systems including the skin patches or infusion pumps are also associated with several disadvantages (41-44). Moreover, alteration in dopamine receptor sensitivity in the basal ganglia may result in the development of adverse effects such as levodopa-induced dyskinesia $(45,46)$. In recent years, application of nanotechnology either alone or in combination with other therapeutic options including deep brain stimulation, targeted cell transplantation, and gene delivery has attracted a considerable interest. Using nanotech-based approaches, it would be possible to design devices which provide neuroprotection by promoting the regeneration of damaged neurons or facilitate the delivery of drugs across the BBB (47). Application of the nanosensors results to the monitoring of the mechanisms of cell death or detection of the neurotransmitter levels within the specific brain regions leading to the early diagnosis of the disease as well as identification of novel drug targets (25). Based on the potential implication of oxidative damage in the pathophysiology of Parkinson's disease, the therapeutic potential of fullerenes which exhibit antioxidant effects was investigated in the experimental models of the disease. Fullerene treatment showed a significant neuroprotective effect in 1-methyl-4-phenylpyridinium (MPP+)exposed mesencephalic dopaminergic neurons $(48,49)$. In an in vivo intranigral iron-infusion model of Parkinson's disease, administration of antioxidant carboxyfullerene prevented the degeneration of tyrosine hydroxylase-positive striatal neurons (50) indicating the therapeutic significance of fullerenes in Parkinson's disease. 
Application of the antisense oligonucleotide with functionalized nanogels has provided an efficient transport system into the brain that may facilitate the inhibition of activity of monoamine oxidase-B (51). This, might enhance dopaminergic neurotransmission which is of therapeutic significance in Parkinson's disease. Moreover, using nanotech-based gene delivery approaches may promote the survival of nigrostriatal dopaminergic neurons or elevate the striatal dopamine content. As previously reported, gene delivery vectors promote the regenerative capacity within the brain (52). Genes may also be delivered via the liposomes. In animal model of Parkinson's disease, the delivery of tyrosine hydroxylase gene through the pegylated immunoliposome has restored the enzyme activity and motor function (53). Using polycations including the polylysine oligomers, DNA may be entrapped into the nanoparticles for delivery into the brain (54). In rat striatum lesioned with 6-OHDA, injection of DNA nanoparticles encoding glial cell-derived neurotrophic factor (GDNF), a neurotrophic factor for midbrain dopaminergic neurons, has been shown to elevate the survival of grafted embryonic dopaminergic neurons and behavioral improvement (55). Furthermore, GDNF-loaded carbon nanotubes are able to elevate the integration of transplanted cells into the striatum (56). Carbon nanotubes loaded with nerve growth factor (NGF), the prototypic member of the neurotrophin family of proteins, which is critically involved in the cell growth, proliferation, and differentiation and mediates the therapeutic effects of a wide variety of CNS drugs (57-61), are able to promote neurite outgrowth in dorsal root ganglion neurons or $\mathrm{PC}_{12}$ cells (62) indicating their therapeutic potential against the neurological disorders. Moreover, electrical stimulation of carbon nanotubes promotes the neuronal activity and deep brain stimulation (63) that might be useful in Parkinson's disease. Quantum dots, the biocompatible semiconductor nanocrystals, are used for molecular imaging and targeted therapy. Since the imbalanced neural activity is implicated in the pathogenesis of CNS disorders, therefore, quantum dots by generating brain signals and affecting the ion channel activity or signalling pathways may restore the normal neuronal activity (64) that would be of therapeutic significance in various brain disorders including the Parkinson's disease.

\section{APPLCATION OF NANOTECHNOLOGY IN THE DIAGNOSIS AND TREATMENT OF MULTIPLE SCLEROSIS}

Multiple sclerosis (MS) is an autoimmune condition in which T lymphocytes cross over the broken BBB and attack the myelin leading to a gradual demyelination of neurons in the spinal cord and brain. Physical disability and neurological symptoms associated to MS may be managed by disease-modifying drugs, however, the disease process will not stop (65). In recent years, advances in nanomedicine have provided greater diagnostic and treatment accuracy. Multifunctional nanocarriers with targeting agents or magnetic nanoparticles may be used for early diagnosis and imaging the lesions $(66,67)$. Superparamagnetic particles of iron oxide (SPIO) have been successfully applied for tracking the labeled cells within the target tissues (68). Moreover, the photoacoustic microscopy provides highresolution and noninvasive imaging of the brain (69).

The reduced perfusion is a typical feature of MS that might be involved in the axonal damage and oxidative stress (70). Since the efficiency of the conventional treatment strategies has remained a challenging issue, therefore, application of the targeting strategies such as the site-specific ligand binding may increase the drug penetration into the brain. In this context, application of the nanomaterials for delivery of CNS-targeted neurotherapeutics has been shown to promote the neural elongation and survival (71). Using the purified carbon nanotubes as scaffolds induces the formation of nanotube-neuron hybrid networks and improve the neuronal performance. Furthermore, interaction of carbon nanotubes with stem cell lineage may improve the cell behaviour (72). Therefore, carbon nanotubes may be successfully applied in nerve tissue engineering that might be of therapeutic importance in MS. Fullerenes may also be promising therapeutic candidates in MS because of their free radical scavenging activity leading to the antioxidant and neuroprotective effects. Evidence from the animal models of MS indicate that fullerene derivatives by the inhibition of glutamate receptors prevent glutamate-induced intracellular calcium increase and neuronal excitotoxicity $(73,74)$. Using polyamidoamine dendrimers for targeted drug delivery into the brain, it has been shown that localization of a drug in activated astrocytes and microglia may suppress the neuroinflammation in MS affected brain leading to a significant improvement of motor function (75).

Nanotechnology may also be applied in the neurosurgery of MS lesions. In this sense, nanosurgery along with the application of nanoneuromodulators, nanoscale magnetic materials, and nanoimaging may result in the significant neuroprotective effects and promote the synaptic connections (76). Nevertheless, the early diagnosis of MS appears the best approach for the prevention of the irreversible disabilities of the disease. This, would be possible using nanoimaging techniques for the detection of any defect at cellular or subcellular level. 


\section{APPLICATION OF NANOTECHNOLOGY IN THE SPINAL CORD INJURY}

Although the adult spinal cord appears to be capable of axonal sprouting and functional reorganization, SCI usually leads to the permanent paralysis because of the inability of axons to regenerate across the lesion. Furthermore, several factors including the process of tissue remodelling and migration of reactive astrocytes to the lesion site prevent the intrinsic regenerative capacity of the spinal cord (77). There are various experimental approaches for the regeneration and reconstruction of damaged spinal cord including the application of neuroprotective or neurotrophic agents and cell therapy (77a), a promising approach for treating a variety of CNS disorders. In SCI, stem cells or progenitor cells including the embryonic stem cells (ESCs), olfactory ensheathing cells (OECs), Schwann cells, and neural progenitor cells may be used for transplantation. Meanwhile, the multipotent mesenchymal stem cells (MSCs) appear more advantageous for clinical applications as they are easily expanded and isolated and exert immunomodulatory effects $(78,79)$. Following the intravenous injection or transplantation into the nervous tissue, MSCs migrate towards the site of injury and reduce the lesion volume leading to the functional improvement (80). Meanwhile, screening the grafted cells in vivo is the essential feature of a successful cell transplantation. In this respect, application of SPIO nanoparticles which may be visualized by MRI and are easily detected in tissue(s) might be so useful. These nanoparticles are consisted of crystalline iron oxide core, a polymer shell, and dextran for surface coating which prevents particle aggregation $(81,82)$. Dextran-coated SPIO nanoparticles have been approved by the US food and drug administration (FDA) and are commercially available as contrast agents (83). Schwann cells and OECs labelled with dextran-coated SPIO have been shown to induce the remyelination of axons following the transplantation into the demyelinated lesions in rat spinal cord $(84,85)$. Biomaterials including the stem cell-seeded hydrogels may be used for grafting of the dissociated cells. In recent years, synthetic biodegradable porous hydrogels have been developed to increase cell growth, differentiation, or adhesion. Hydrogels of poly (2-hydroxypropyl)-methacrylamide (PHPMA) implanted into the spinal cord lesion provide a scaffold for tissue regeneration (86). In the case of large lesions, cell transplantation alone is not enough for tissue regeneration and it is essential to bridge the lesion site with a permissive environment which fills the cavity and enables axonal growth. In this respect, nanofibers which may be conjugated to drugs or growth factors are suitable candidates for promoting the neural regeneration. Indeed, development of nanofiber materials has been an exciting innovation in tissue regeneration and drug delivery. The porous structure of the nanofibrous network mimics the architecture of the extracellular matrix. In addition, the high surface area to volume ratio may increase the cell proliferation, differentiation, and adhesion. Using electrospinning technique, various electrospun-nanofibers have been developed as the potential scaffolds for neural tissue engineering $(87,88)$. Scaffolds based on the layers of polymer nanofibers in the case of implantation into the hemisected spinal cord leads to the formation of blood vessels and neural cell processes (89). Moreover, seeding of embryonic spinal cord cells into a nanofiber scaffold promotes the regeneration in the transected rat spinal cord (90).

\section{APPLICATION OF NANOTECHNOLOGY FOR THE MANAGEMENT OF AMYOTROPHIC LATERAL SCLEROSIS}

Amyotrophic lateral sclerosis (ALS) is a motor neuron disease which is caused by the degeneration of lower motor neurons in the spinal cord and/or upper motor neurons in the cerebral cortex. Diagnosis and treatment of ALS has still remained as a major challenge in medicine and symptomatic management is the mainstay of treatment in this progressive neurodegenerative disorder (91). Following the development of a mouse model of the disease, considerable efforts have been made to design more efficient therapeutic agents. In this context, cerium oxide $\left(\mathrm{CeO}_{2}\right)$ nanoparticles have been produced which are able to reduce free radical-induced damage. $\mathrm{CeO}_{2}$ nanoparticles are able to protect the cultured motor neuron-like cells against oxidative stress and exhibit neuroprotective effects (92) suggesting the therapeutic significance of these nanoparticles in CNS disorders including ALS.

\section{LIPID NANOPARTICLES: STATE-OF-THE-ART CARRIER SYSTEMS IN PHARMACEUTICAL NANOTECHNOLOGY}

In recent years, considerable research efforts have been made to develop the optimized nanocarriers in order to overcome the potential problems associated with the previously developed nanomaterials. In this respect, lipid-based colloidal drug delivery systems including the solid lipid nanoparticles (SLNs) and nanostructured lipid carriers (NLCs) have been developed as the alternative carrier systems to the polymeric nanoparticles, emulsions, and liposomes. Drugs or other active ingredients are protected from the enzymatic degradation when loaded within the lipid nanoparticles. Furthermore, targeted drug delivery and controlled release from the lipid matrix leads to an improved pharmacologic profile. Lipid nanoparticles by increasing the absorption 
of loaded drug and its residence time in the gastrointestinal tract may be administered orally. They may also be used as vehicles for topical or parenteral drug delivery $(93,94)$. SLNs are the biocompatible colloidal delivery systems with several advantages, however, drug expulsion during the storage may be occurred due to the lipid polymorphism or crystallization of lipid matrix. In addition, SLNs have shown limited drug loading capacity (95). Therefore, NLCs which are a mixture of solid and liquid lipids with imperfect matrix structure were developed to overcome the disadvantages of SLNs. NLCs are characterized by good biocompatibility, long-term stability, controlled drug release, and high drug loading efficiency leading to the reduction of drug dosage and adverse effects. NLCs are promising carriers for poorly water-soluble drugs that may be due to their potential to elevate the solubility of lipophilic drug (96). NLCs have been used as a sustained-release drug carrier system for the treatment of leukemia (97), antifungal activity (98), psoriasis (99) and tumor targeting (100). In human hepatocarcinoma cells, entrapment of the inhibitor of epidermal growth factor receptor (tyrphostin AG-1478) into the NLCs has resulted to a remarkable therapeutic effect (101). NLCs which may be produced on large scale, have been loaded with various therapeutic agents in our laboratory in order to investigate their effects in the ischemic stroke and brain cancer. The promising primary findings represent them as suitable CNStargeted drug delivery systems in neurological disorders.

\section{CONCLUSION}

The enormous research efforts in the multidisciplinary field of nanotechnology have resulted in the amazing growth in the production of highly-advanced biomaterials and nanodevices including the novel gene or drug delivery systems to overcome the BBB and provide more efficient treatments. Using this cutting-edge technology, a comprehensive knowledge about the pathophysiology of neurological diseases has been obtained. Application of the sophisticated delivery systems of various drugs, growth factors and stem cells have been shown to promote the regeneration of damaged tissues that might lead to a better prospect for the treatment of neurological disorders. In addition, progress being made in the field of biomedical nanotechnology has led to the development of biomaterials which are able to interact with biological systems at sub-cellular levels that may be of both basic and clinical significance in the theranostics of various pathological conditions including the neurodegenerative diseases.

\section{REFERENCES}

1. Bramlett HM, Dietrich WD. Progressive damage after brain and spinal cord injury: pathomechanisms and treatment strategies. Prog Brain Res 2007; 161: 125-141. DOI:10.1016/S0079-6123(06)61009-1.

2. Feynman RP. There's plenty of room at the bottom. Eng Sci (Cal Tech) 1960; 594: 22-36. 3. Freitas Jr RA. Nanotechnology, nanomedicine and nanosurgery. Int J Surg 2005; 3: 243-246. DOI:10.1016/j.ijsu.2005.10.007.

4. Jain KK. Role of nanotechnology in developing new therapies for diseases of the nervous system. Nanomedicine (Lond) 2006; 1: 9-12. DOI:10.2217/17435889.1.1.9.

5. Silva GA. Neuroscience nanotechnology: progress, opportunities and challenges. Nat Rev Neurosci 2006; 7: 65-74. DOI:10.1038/nrn1827.

6. Abbott NJ, Ronnback L, Hansson E. Astrocyte-endothelial interactions at the blood-brain barrier. Nat Rev Neurosci 2006; 7: 41-53. DOI:10.1038/nrn1824.

7. De Rosa G, Salzano G, Caraglia M, Abbruzzese A. Nanotechnologies: a strategy to overcome bloodbrain barrier. Curr Drug Metab 2012; 13: 61-69. DOI: 10.2174/138920012798356943.

8. Hassanzadeh P, Fullwood I, Sothi S, Aldulaimi D. Cancer nanotechnology. Gastroenterol Hepatol Bed Bench 2011; 4: 63-69. PMCID: PMC4017405.

9. Franklin RJM, Ffrench-Constant C. Remyelination in the CNS: from biology to therapy. Nat Rev Neurosci 2008; 9: 839-855. DOI: 10.1038/nrn2480.

10. Patel T, Zhou J, Piepmeier JM, Saltzman WM. Polymeric nanoparticles for drug delivery to the central nervous system. Adv Drug Deliv Rev 2012; 64: 701-705. DOI: 10.1016/j.addr.2011.12.006.

11. Qiu L, Zheng C, Jin Y, Zhu K. Polymeric micelles as nanocarriers for drug delivery. Expert Opin Ther Pat 2007; 17: 819-830. DOI:10.1517/13543776.17.7.819.

12. Sun NF, Meng QY, Tian AL, Hu SY, Wang RH, Liu ZX, et al. Nanoliposome mediated FL/TRAIL double-gene therapy for colon cancer: in vitro and in vivo evaluation. Cancer Lett 2012; 315: 69-77. DOI:10.1016/j.canlet.2011.10.010.

13. Jan E, Kotov NA. Successful differentiation of mouse neural stem cells on layer by layer assembled singlewalled carbon nanotube composite. Nano Lett 2007; 7: 1123-1128. DOI: 10.1021/n10620132.

14. Hassanzadeh P. Tissue engineering and growth factors. Updated evidence. Biomed Rev 2012; 23: 19-35. DOI: http://dx.doi.org/10.14748/bmr.v23.26 
15. Fernandes R, Gracias DH. Self-folding polymeric containers for encapsulation and delivery of drugs. $A d v$ Drug Deliv Rev 2012; 64:1579-1589. DOI: 10.1016/j. addr.2012.02.012.

16. Hassanzadeh P. Computational modelling: Moonlighting on the neuroscience and medicine. Biomed Rev 2013; 24: 25-31. DOI: http://dx.doi.org/10.14748/bmr.v24.19

17. Lin $H$, Bhatia R, Lal R. Amyloid $\beta$ protein forms ion channels: implications for Alzheimer's disease pathophysiology. FASEB J 2001; 15: 2433-2444. DOI: 10.1096/ fj.01-0377com.

18. LeBlanc AC. The role of apoptotic pathways in Alzheimer's disease neurodegeneration and cell death. Curr Alzheimer Res 2005; 2: 389-402. DOI: 10.2174/156720505774330573.

19. Masters CL, Cappai R, Barnham KJ, Villemagne VL. Molecular mechanisms for Alzheimer's disease: implications for neuroimaging and therapeutics. $J$ Neurochem 2006; 97: 1700-1725. DOI: 10.1111/j.14714159.2006.03989.x.

20. Mattson MP. Pathways towards and away from Alzheimer's disease. Nature 2004; 430: 631-639. DOI: 10.1038/nature02621.

21. Arimon M, Diez-Perez I, Kogan MJ, Durany N, Giralt E, Sanz F, et al. Fine structure study of A $\beta 1-42$ fibrillogenesis with atomic force microscopy. FASEB $J$ 2005; 19 : 1344-1346. DOI: 10.1096/fj.04-3137fje.

22. Kinoshita A, Fukumoto H, Shah T, Whelan CM, Irizarry MC, Hyman BT. Demonstration by FRET of BACE interaction with the amyloid precursor protein at the cell surface and in early endosomes. J Cell Sci 2003; 116: 3339-3346. DOI: $10.1242 /$ jcs.00643.

23. Georganopoulou DG, Chang L, Nam JM, Thaxton CS, Mufson EJ, Klein WL, et al. Nanoparticlebased detection in cerebral spinal fluid of a soluble pathogenic biomarker for Alzheimer's disease. Proc Natl Acad Sci USA 2005; 102: 2273-2276. DOI: 10.1073/pnas.0409336102.

24. Irizarry MC. Biomark ers of Alzheimer disease in plasma. NeuroRx 2004; 1: 226-234. DOI: 10.1602/neurorx.1.2.226.

25. Hassanzadeh P. New perspectives in biosensor technology. Gastroenterol Hepatol Bed Bench 2010; 3: 105-107.

26. Dugan LL, Turetsky DM, Du C, Lobner D, Wheeler M, Almli CR, et al. Carboxyfullerenes as neuroprotective agents. Proc Natl Acad Sci USA 1997; 94: 9434-9439. PMCID: PMC23208.

27. Podolski IY, Podlubnaya ZA, Kosenko EA, Mugantseva EA, Makarova EG, Marsagishvili LG, et al. Effects of hydrated forms of C60 fullerene on amyloid 1-peptide fibrillization in vitro and performance of the cognitive task. J Nanosci Nanotechnol 2007; 7: 1479-1485. PMID:17450915.

28. Pai AS, Rubinstein I, Onyuksel H. PEGylated phospholipid nanomicelles interact with $\beta$-amyloid $(1-42)$ and mitigate its $\beta$-sheet formation, aggregation and neurotoxicity in vitro. Peptides 2006; 27: 2858-2866. DOI:10.1016/j. peptides.2006.04.022.

29. Cui Z, Lockman PR, Atwood CS, Hsu CH, Gupte A, Allen $\mathrm{DD}$, et al. Novel d-penicillamine carrying nanoparticles for metal chelation therapy in Alzheimer's and other CNS diseases. Eur J Pharm Biopharm 2005; 59: 263-272. DOI:10.1016/j.ejpb.2004.07.009.

30. Liu G, Garrett G, Men P, Zhu X, Perry G, Smith MA. Nanoparticle and other metal chelation therapeutics in Alzheimer disease. Biochem Biophys Acta 2005; 1741: 246-252. DOI:10.1016/j.bbadis.2005.06.006.

31. Liu G, Men P, Harris PL, Rolston RK, Perry G, Smith MA. Nanoparticle iron chelators: a new therapeutic approach in Alzheimer disease and other neurologic disorders associated with trace metal imbalance. Neurosci Lett 2006; 406: 189-193. DOI:10.1016/j.neulet.2006.07.020

32. Ikeda K, Okada T, Sawada S, Akiyoshi K, Matsuzaki K. Inhibition of the formation of amyloid $\beta$-protein fibrils using biocompatible nanogels as artificial chaperones. FEBS Lett 2006; 580: 6587-6595. DOI:10.1016/j. febslet.2006.11.009.

33. Boridy S, Takahashi H, Akiyoshi K, Maysinger. D. The binding of pullulan modified cholesterylnanogels to $A \beta$ oligomers and their suppression of cytotoxicity. Biomaterials 2009; 30: 5583-5591. DOI:10.1016/j.biomaterials.2009.06.010.

34. Taylor M, , Moore S, Mourtas S, Niarakis A, Re F, Zona $\mathrm{C}$, et al. Effect of curcumin-associated and lipid ligandfunctionalized nanoliposomes on aggregation of the Alzheimer's A $\beta$ peptide. Nanomedicine 2011; 7: 541-550. DOI:10.1016/j.nano.2011.06.015.

35. Mourtas S, Canovi M, Zona C, Aurilia D, Niarakis A, La Ferla B, et al. Curcumin-decorated nanoliposomes with very high affinity for amyloid- $\beta 1-42$ peptide. Biomaterials 2011; 32: 1635-1645. DOI: 10.1016/j.biomaterials.2010.10.027.

36. Yang Z, Zhang Y, Yang Y, Sun L, Han D, Li H, et al. Pharmacological and toxicological target organelles and safe use of single-walled carbon nanotubes as drug carriers in treating Alzheimer disease. Nanomedicine 2010; 6: 427-441. DOI: 10.1016/j.nano.2009.11.007. 
37. Kim HR, Andrieux K, Gil S, Taverna M, Chacun H, Desmaële $\mathrm{D}$, et al. Translocation of poly(ethylene glycol-co-hexadecyl)cyanoacrylate nanoparticles into rat brain endothelial cells: role of apolipoproteins in receptor-mediated endocytosis. Biomacromolecules 2007; 8: 793-799. DOI: 10.1021/bm060711a.

38. Wilson B, Samanta MK, Santhi K, Kumar KP, Paramakrishnan N, Suresh B. Poly(n-butylcyanoacrylate) nanoparticles coated with polysorbate 80 for the targeted delivery of rivastigmine into the brain to treat Alzheimer's disease. Brain Res 2008; 1200: 159-168. DOI: 10.1016/j. brainres.2008.01.039.

39. Joshi SA, Chavhan SS, Sawant KK. Rivastigmine-loaded PLGA and PBCA nanoparticles: preparation, optimization, characterization, in vitro and pharmacodynamic studies. Eur J Pharm Biopharm 2010; 76: 189-199. DOI: 10.1016/j.ejpb.2010.07.007.

40. Schrag A, Quinn NP, Ben-Shlomo Y. Heterogeneity of Parkinson's disease. J Neurol Neurosurg Psychiatry 2006; 77: 275-276. PMCID: PMC2077583.

41. Lefaucheur JP, Gurruchaga JM, Pollin B, von Raison F, Mohsen N, Shin M, et al. Outcome of bilateral subthalamic nucleus stimulation in the treatment of Parkinson's disease: correlation with intra-operative multi-unit recordings but not with the type of anaesthesia. Eur Neurol 2008; 60: 186-99. DOI: 10.1159/000148246.

42. Paul G, Meissner W, Rein S, Harnack D, Winter C, Hosmann $\mathrm{K}$, et al. Ablation of the subthalamic nucleus protects dopaminergic phenotype but not cell survival in a rat model of Parkinson's disease. Exp Neurol 2004; 185 : 272-280. DOI:10.1016/S0014-4886(03)00363-7.

43. Hilker R, Portman AT, Voges J, Staal MJ, Burghaus L, van Laar $\mathrm{T}$, et al. Disease progression continues in patients with advanced Parkinson's disease and effective subthalamic nucleus stimulation. J Neurol Neurosurg Psychiatry 2005; 76: 1217-1221. DOI: 10.1136/jnnp.2004.057893.

44. Fraix V, Houeto JL, Lagrange C, Le Pen C, Krystkowiak $\mathrm{P}$, Guehl D, et al. Clinical and economic results of bilateral subthalamic nucleus stimulation in Parkinson's disease. J Neurol Neurosurg Psychiatry 2006; 77: 443-449. DOI: 10.1136/jnnp.2005.077677.

45. Vingerhoets FJ, Villemure JG, Temperli P, Pollo C, Pralong E, Ghika J. Subthalamic DBS replaces levodopa in Parkinson's disease: two-year follow up. Neurology 2002; 58: 396-401. DOI: 1526-632X.

46. Moro E, Esselink RJ, Benabid AL, Pollak P. Response to levodopa in parkinsonian patients with bilateral subthalamic nucleus stimulation. Brain 2002; 125: 2408-2417.
DOI: http://dx.doi.org/10.1093/brain/awf249.

47. Ulbrich K, Hekmatara T, Herbert E, Kreuter J. Transferrin- and transferrin receptor- antibody-modified nanoparticles enable drug delivery across the blood-brain barrier (BBB). Eur J Pharm Biopharm 2009; 71: 251-256. DOI: 10.1016/j.ejpb.2008.08.021.

48. Dugan LL, Lovett EG, Quick KL, Lotharius J, Lin TT, O’Malley KL. Fullerene-based antioxidants and neurodegenerative disorders. Parkinsonism Relat Disord 2001; 7 : 243-246. DOI:10.1016/S1353-8020(00)00064-X.

49. Lotharius J, Duga LL, O’Malley KL. Distinct mechanisms underlie neurotoxin-mediated cell death in cultured dopaminergic neurons. J Neurosci 1999; 1284-1293. PMID: 9952406.

50. Lin AM, , Chyi BY, Wang SD, Yu HH, Kanakamma PP, Luh TY, et al. Carboxyfullerene prevents iron-induced oxidative stress in rat brain. $J$ Neurochem $1999 ; 72$ : 1634-1640. DOI: 10.1046/j.1471-4159.1999.721634.x.

51. Vinogradov SV, Batrakova EV, Kabanov AV. Nanogels for oligonucleotide delivery to the brain. Bioconjug Chem 2004; 15: 50-60. DOI: 10.1021/bc034164r.

52. Witt J, Marks WJ. An update on gene therapy in Parkinson's disease. Curr Neurol Neurosci Rep 2011; 11: 362-370. DOI: 10.1007/s11910-011-0197-8.

53. Zhang Y, Calon F, Zhu C, Boado RJ, Pardridge WM. Intravenous nonviral gene therapy causes normalization of striatal tyrosine hydroxylase and reversal of motor impairment in experimental parkinsonism. Hum Gene Ther 2003; 14: 1-12. DOI:10.1089/10430340360464660.

54. Nitta SK, Numata K. Biopolymer-Based Nanoparticles for Drug/Gene Delivery and Tissue Engineering. Int $J \mathrm{Mol}$ Sci 2013; 14: 1629-1654. DOI: 10.3390/ijms14011629.

55. Yurek DM, Flectcher AM, Kowalczyk TH, Padegimas L, Cooper MJ. Compacted DNA nanoparticle gene transfer of GDNF to the rat striatum enhances the survival of grafted fetal dopamine neurons. Cell Transp 2009; 18: 1183-1196. DOI: $10.3727 / 096368909 X 12483162196881$.

56. Mazzatenta A, Giugliano M, Campidelli S, Gambazzi L, Businaro L, Markram $\mathrm{H}$, et al. Interfacing neurons with carbon nanotubes: electrical signal transfer and synaptic stimulation in cultured brain circuits. J Neurosci 2007; 27 : 6931-6936. DOI:10.1523/JNEUROSCI.1051-07.2007.

57. Hassanzadeh P, Hassanzadeh A. Involvement of the neurotrophin and cannabinoid systems in the mechanisms of action of neurokinin receptor antagonists. Eur Neuropsychopharmcol 2011; 21: 905-917. DOI: 10.1016/j. euroneuro.2011.01.002.

58. Hassanzadeh P, Rahimpour S. The cannabinergic system 
is implicated in the upregulation of central NGF protein by psychotropic drugs. Psychopharmacology 2011; 215: 129-141. DOI: 10.1007/s00213-010-2120-4.

59. Hassanzadeh P, Hassanzadeh A. Effects of different psychotropic agents on the central nerve growth factor protein. Iran J Basic Med Sci 2010; 13: 202-209. ISSN: 2008-3866.

60. Hassanzadeh P, Hassanzadeh A. Implication of NGF and endocannabinoid signalling in the mechanism of action of sesamol: a multi-target natural compound with therapeutic potential. Psychopharmacology 2013; 229: 571-578. DOI: $10.1007 / \mathrm{s} 00213-013-3111-\mathrm{z}$.

61. Hassanzadeh $\mathrm{P}$, Hassanzadeh $\mathrm{A}$. The $\mathrm{CB}_{1}$ receptormediated endocannabinoid signaling and NGF: the novel targets of curcumin. Neurochem Res 2012; 37: 1112-1120. DOI: $10.1007 / \mathrm{s} 11064-012-0716-2$.

62. Chen W, Xiong Q, Ren Q, Guo Y, Li G. Can aminofunctionalized carbon nanotubes carry functional nerve growth factor? Neural Regen Res 2014; 9: 285-292. DOI: 10.4103/1673-5374.128225.

63. Andrews R. Neuroprotection at the nanolevel- Part I Introduction to nanoneurosurgery. Ann NY Acad Sci 2007; 1122: 169-184. DOI: 10.1196/annals.1403.012.

64. Lugo K, Miao X, Rieke F, Lin LY. Remote switching of cellular activity and cell signaling using light in conjunction with quantum dots. Biomed Opt Exp 2012; 3: 447-454. DOI: 10.1364/BOE.3.000447.

65. Comston A, Coles A. Multiple sclerosis. Lancet 2002; 359: 1221-1231. DOI:10.1016/S0140-6736(02)08220-X.

66. Henderson APD, Barnett MH, Parratt JDE, Prineas JW. Multiple sclerosis: distribution of inflammatory cells in newly forming lesions. Ann Neurol 2009; 66: 739-753. DOI: $10.1002 /$ ana.21800.

67. Heta Y, Kumaki K, Hifumi H, Citterio D, Tanimoto A, Suzuki K. Gadolinium containing photochromic micelles as potential magnetic resonance imaging traceable drug carriers. Photochem Photobiol 2012; 88: 876-883. DOI: 10.1111/j.1751-1097.2012.01124.x.

68. Richards JM, Shaw CA, Lang NN, Williams MC, Semple SI, MacGillivray TJ, et al. In vivo mononuclear cell tracking using superparamagnetic particles of iron oxide feasibility and safety in humans. Circulation 2012; 5: 509-517. DOI: 10.1161/CIRCIMAGING.112.972596.

69. Zhang HF, Maslov K, Stoica G, Wang V. Functional photoacoustic microscopy for high-resolution and noninvasive imaging. Nat Biotech 2006; 24: 24848-24851. DOI:10.1038/nbt1220.

70. Zivadinov R, Ramanathan M, Dolic K, Marr K, Karmon $\mathrm{Y}$, Siddiqui $\mathrm{AH}$, et al. Chronic cerebrospinal venous in- sufficiency inmultiple sclerosis: diagnostic, pathogenetic, clinical and treatment perspectives. Expert Rev Neurother 2011; 11: 1277- 1294. DOI: 10.1586/ern.11.117.

71. Srikanth M, Kessler JA. Nanotechnology-novel therapeutics for CNS disorders. Nat Rev Neurol 2012; 8: 307-318. DOI: 10.1038/nrneurol.2012.76.

72. Cellot G, Cilia E, Cipollone S, Rancic V, Sucapane A, Giordani S, et al. Carbon nanotubes might improve neuronal performance by favouring electrical shortcuts. Nat Nanotech 2009; 4: 126-133. DOI: 10.1038/nnano.2008.374.

73. Ali SS, Hardt JI, Dugan LL. SOD Activity of carboxyfullerenes predicts their neuroprotective efficacy: a structure-activity study. Nanomedicine 2008; 4: 283-294. DOI: 10.1016/j.nano.2008.05.003.

74. Dugan LL, Lovett EG, Quick KL, Lotharius J, Lin TT, O’Malley KL. Fullerene-based antioxidants and neurodegenerative disorders. Parkinsonism Relat Disord 2001; 7 : 243-246. DOI:10.1016/S1353-8020(00)00064-X.

75. Dai H, Navath RS, Balakrishnan B, Guru BR, Mishra MK, Romero R, et al. Intrinsic targeting of inflammatory cells in the brain by polyamidoamine dendrimers upon subarachnoid administration. Nanomedicine 2010; 5: 1317-1329. DOI: $10.2217 / \mathrm{nnm} .10 .89$.

76. Khawaja AM. The legacy of nanotechnology: revolution and prospects in neurosurgery. Int J Surg 2011; 9: 608-614. DOI: 10.1016/j.ijsu.2011.10.002.

77. Bramlett HM, Dietrich WD. Progressive damage after brain and spinal cord injury: pathomechanisms and treatment strategies. Prog Brain Res 2007; 161: 125-141. DOI:10.1016/S0079-6123(06)61009-1.

77a. Aloe L, Bianchi P, De Bellis A, Soligo M, Rocco ML. Intranasal nerve growth factor bypasses the blood-brain barrier and affects spinal cord neurons in spinal cord injury. Neural Regen Res 2014; 9:1025-1030. DOI: 10.4103/1673-5374.133161.

78. Cummings BJ, Uchida N, Tamaki SJ, Salazar DL, Hooshmand M, Summers R, et al. Human neural stem cells differentiate and promote locomotor recovery in spinal cord-injured mice. Proc Nat Acad Sci USA 2005; 102: 14069-14074. DOI: 10.1073/pnas.0507063102.

79. Dey ND, Bombard MC, Roland BP, Davidson S, Lu M, Rossignol $\mathrm{J}$, et al. Genetically engineered mesenchymal stem cells reduce behavioural deficits in the YAC 128 mouse model of Huntington's disease. Behav Brain Res 2010; 214: 193-200. DOI: 10.1016/j.bbr.2010.05.023.

80. Binan L, Ajji A, De Crescenzo G, Jolicoeur M. Approaches for neural tissue regeneration. Stem Cell Rev Rep 2014; 10: 44-59. DOI: 10.1007/s12015-013-9474-z. 
81. Shubayev VI, Pisanic TR, Jin S. Magnetic nanoparticles for theragnostics. Adv Drug Deliv Rev 2009; 61: 467-477. DOI: 10.1016/j.addr.2009.03.007.

82. Santra S, Kaittanis C, Grimm J, Perez JM. Drug/dyeloaded, multifunctional iron oxide nanoparticles for combined targeted cancer therapy and dual optical/magnetic resonance imaging. Small 2009; 5: 1862-1868. DOI: 10.1002/smll.200900389.

83. Lu M, Cohen MH, Rieves D, Pazdur R. FDA report: ferumoxytol for intravenous iron therapy in adult patients with chronic kidney disease. Am J Hematol 2010; 85: 315-319. DOI: 10.1002/ajh.21656.

84. Xia L, Wan H, Hao SY, Li DZ, Chen G, Gao CC, et al. Co-transplantation of neural stem cells and Schwann cells within poly (L-lactic-coglycolic acid) scaffolds facilitates axonal regeneration in hemisected rat spinal cord. Chin Med J 2013; 126: 909-917. PMID: 23489801.

85. Senpan A, Caruthers SD, Rhee I, Mauro NA, Pan D, Hu $\mathrm{G}$, et al. Conquering the dark side: colloidal iron oxide nanoparticles. ACS Nano 2009; 3: 3917-3926. DOI: $10.1021 / \mathrm{nn} 900819 \mathrm{y}$.

86. Woerly S, Petrov P, Sykova E, Roitbak T, Simonova $Z$, Harvey AR. Neural tissue formation within porous hydrogels implanted in brain and spinal cord lesions: ultrastructural, immunohistochemical, and diffusion studies. Tissue Eng 1999; 5: 467-488. PMID:10586102.

87. Yoo HS, Kim TG, Park TG. Surface-functionalized electrospun nanofibers for tissue engineering and drug delivery. Adv Drug Deliv Rev 2009; 61: 1033-1042. DOI: 10.1016/j.addr.2009.07.007.

88. Huang SH, Chien TC, Hung KY. Selective deposition of electrospun alginate-based nanofibers onto cellrepelling hydrogel surfaces for cell-based microarrays. Curr Nanosci 2011; 7: 267-274. DOI: http://dx.doi. org/10.2174/157341311794653703.

89. Liu T, Xu J, Chan BP, Chew SY. Sustained release of neurotrophin-3 and chondroitinase $\mathrm{ABC}$ from electrospun collagen nanofiber scaffold for spinal cord injury repair. $J$ Biomed Mater Res A 2012; 100: 236-242. DOI: 10.1002/ jbm.a.33271.

90. Rochkind S, Shahar A, Fliss D, El-Ani D, Astachov L, Hayon T, et al. Development of a tissue engineered composite implant for treating traumatic paraplegia in rats. Eur Spine J 2006; 15: 234-245. DOI: 10.1007/s00586005-0981-8.

91. Bruijn LI, Cudkowicz M. Therapeutic targets for amyotrophic lateral sclerosis: current treatments and prospects for more effective therapies. Expert Rev Neurother 2006; 6: 417-428. DOI: 10.1586/14737175.6.3.417.

92. Schubert D, Dargusch R, Raitano J, Chan SW. Cerium and yttrium oxide nanoparticles are neuroprotective. Biochem Biophys Res Commun 2006; 342: 86-91. DOI:10.1016/j. bbrc.2006.01.129.

93. Fang JY, Fang CL, Liu CH, Su YH. Lipid nanoparticles as a vehicles for topical psoralen delivery: Solid lipid nanoparticles (SLN) versus nanostructured lipid carriers (NLC). Eur J Pharm Biopharm 2008; 70: 633-640. DOI: 10.1016/j.ejpb.2008.05.008.

94. Joshi MD, Müller RH. Lipid nanoparticles for parenteral delivery of actives. Eur J Pharm Biopharm 2009; 71: 161-172. DOI: 10.1016/j.ejpb.2008.09.003.

95. Müller RH, Maeder K, Gohla S. Solid lipid nanoparticles (SLN) for controlled drug delivery - a review of the state of the art. Eur J Pharm Biopharm 2000; 50: 161-177. DOI:10.1016/S0939-6411(00)00087-4.

96. Kumbhar DD, Pokharkar VB. Engineering of a nanostructured lipid carrier for the poorly water-soluble drug, bicalutamide: Physicochemical investigations. Colloids Surf A Physicochem Eng Asp 2013; 416: 32- 42.

97. Rahman HS, Rasedee HS, How CW, Abdul AB, Zeenathul $\mathrm{NA}$, Othman $\mathrm{HH}$, et al. Zerumbone-loaded nanostructured lipid carriers: preparation, characterization, and antileukemic effect. Int J Nanomed 2013; 8: 2769-2781. DOI: $10.2147 /$ IJN.S54346.

98. Mendes AI, Silva AC, Catita JAM, Cerqueira F, Gabriel C, Lopes CM. Miconazole-loaded nanostructured lipid carriers (NLC) for local delivery to the oral mucosa: Improving antifungal activity. Colloids Surf B: Biointerfaces 2013; 111: 755- 763. DOI: 10.1016/j. colsurfb.2013.05.041.

99. Fang JY, Fang CL, Liu CH, Su YH. Lipid nanoparticles as vehicles for topical psoralen delivery: Solid lipid nanoparticles (SLN) versus nanostructured lipid carriers (NLC). Eur J Pharm Biopharm 2008: 70: 633-640. DOI: 10.1016/j.ejpb.2008.05.008.

100. Shenoy VS, Vijay IK, Murthy RS. Tumour targeting: biological factors and formulation advances in injectable lipid nanoparticles. J Pharm Pharmacol 2005; 57 : 411-421. PMID: 15831200.

101. Bondì ML, Azzolina A, Craparo EF, Botto C, Amore E, Giammona G, et al. Entrapment of an EGFR inhibitor into nanostructured lipid carriers (NLC) improves its antitumor activity against human hepatocarcinoma cells. J Nanobiotech 2014; 12: 21. DOI: 10.1186/1477-3155-12-21. 